4) Da nach Anzeige von Hrn. Vicedirector Dr. Fie dl er in Cassel Hr. College Frank in Witzenhausen wegen seiner Kränklichteit das Kreisdirectorium niederzulegen wïnscht, so ist $\mathrm{Hr}$. Apotheker Gu mpert in Eschwege zum Kreisdirector dafür ernannt worden. Dem Hrn. Collegen Frank ist für seine Mühwaltungen um die Anstalt der Dank des Vereins ausgedrückt worden.

5) Es wurde ein Schreiben von Hrn. Vicedirector S ehI meyer vorgelegt, worin er anzeigte, dafs in Folge der Bemihungen des Hrn. Collegen $L o ̈ h r$ in Trier ein neuer Kreis daselbst sich gebildet habe. Hr. Löhr ist zum Kreisdirector dafür erwählt worden.

6) Der Hr. College Sehlm ey er wünschte, bei der Vergröfserung seines Vicedirectoriums in seirıen Geschäften erleichtert zu werden, und deshalb die Geschäfte der Verwaltung des Kreises Cöln abzugeben, hat sich indessen auf unsern $W$ unsch entschlossen, selbige fürs erste noch fortzuführen.

7) Dem Hrn. Schiffer in Essen, invaliden Gehülfen, ist die von Hrn. Vicedirector $K l$ önne nachgesuchte Unterstiutzung auch für das nächste Jahr bewilligt.

8) In Bezug auf die Bestellungen der Bücher für die Lesezirkel werden die betreffenden Herren Beamten ersucht, diese genau den Bestimmungen gemäls zu machen, so dafs die dafür festgesetzte Quote auf keinen Fall überschritten wird.

9) Ein Vorschlag von Hrn. Vicedirector $B_{u}$ cholz in Erfurt, die Gehülfen - Unterstützungsanstalt betreffend, wurde vorgelegt und soll weiter berathen werden.

10) Die Rechnungen der Bucholz - Gehlen - Trommsdorff'schen Stiftung fiur das laufende Jahr wurden durchgenommen und abgeschlossen, und dem Mitvorstande in Erfurt übermacht.

Brandes. E. F. Asch off. Overbeck. L. As ch of $f$.

\title{
Aufforderung, die Einzahlung der Beiträge zur Generalkasse für 1841 betreffend.
}

Die Herren Mitglieder des Vereins werden ersucht, den Jahrsbeitrag zur Generalkasse für 1841 ihren resp. Kreisdirectoren baldigst einzusenden. Nach $\S$. 36. der Statuten mufs dieses vor dem 15. Jan. jedes Jahrs geschehen. Der Beitrag beträgt bekanntlich 5 Thlr. $16 \mathrm{Ggr}$. In dem Bereich derjenigen Postanstalten, wo der Verein besonderer Portovergünstigungen gegen eine Aversionalsumme sich erfreut, zahlt jedes Mitglied aufserdem noch $12 \mathrm{Ggr}$. als Beitrag zur Aufbringung dieser Summe, also im Ganzen $6 \mathrm{Thlr}$. $4 \mathrm{Ggr}$. Die Ordnung des Rechnungswesens, wie des ganzen Vereinshaushalts, nöthigt mich, um die rechtzeitige Einsendung dieser Beiträge dringend zu bitten.

Die Direction der Generalkasse. Dr. E. F. A s ch of $f$. 